\title{
Effect of N-Methyltetrazolethiol on Liver Microsomal gamma-Glutamylcarboxylation: Modification of the In Vitro Action of N-Methyltetrazolethiol
}

\author{
Tatsushi OKA*, Akira TOUCHI and Takashi MATSUBARA \\ Shionogi Research Laboratories, Shionogi \& Co., Ltd., \\ Fukushima-ku. Osaka 553. Japan \\ "Kanzakigawa Laboratory. Shionogi Research Laboratories, Shionogi \& Co., Ltd., \\ Futaba-cho, Toyonaka, Osaka 561, Japan
}

Accepted May 6, 1987

\begin{abstract}
Vitamin K-dependent gamma-glutamylcarboxylation activity in rat liver microsomes was monitored using the incorporation of ${ }^{14} \mathrm{CO}_{2}$ into exogenous pentapeptide and endogenous protein substrates as indicators. Detergent solubilization of the microsomal enzymes was required for the activity to develop, but higher concentrations of detergent inhibited the enzymatic reaction. Pyridoxal-5'phosphate (PAL-P) and dithiothreitol (DTT) stimulated the enzyme activity. The enzyme activity was observed when the hydroquinone form of vitamin $K$ or the quinone form plus NADH was employed as the cosubstrate, but little activity was detected in the reaction system containing vitamin K-epoxide plus NADH plus DTT. N-Methyltetrazolethiol (NMTT), the substituent at the 3 '-position of several beta-lactam antibiotics, inhibited the enzyme activity in vitro only in the reaction system containing NADH. Addition of DTT diminished the in vitro action of NMTT, while PAL-P and detergent did not affect it. The results indicate that the in vitro inhibitory action of NMTT is observable under some specific and restricted assay conditions. This paper also discusses the differences between the in vitro action and the in vivo effect of NMTT.
\end{abstract}

The vitamin K-dependent enzyme gammaglutamylcarboxylase (gamma-carboxylase). in liver microsomes catalyzes the conversion of specific glutamyl residues in the precursor of coagulation factors $I I, V I I, I X$ and $X$ to gamma-carboxyglutamyl residues (1). This enzyme requires $\mathrm{CO}_{2}, \mathrm{O}_{2}$, a glutamyl substrate and the hydroquinone form of vitamin $\mathrm{K}\left(\mathrm{VK}\left[\mathrm{H}_{2}\right]\right)$ for the carboxylation reaction (Fig. 1). The cofactor $\vee \mathrm{K}\left[\mathrm{H}_{2}\right]$ is oxidized to the corresponding vitamin K-2,3-epoxide (VK[O]) during this gamma-carboxylation reaction. Another microsomal enzyme, vitamin $K$ epoxide reductase, converts this $\mathrm{VK}[\mathrm{O}]$ to the quinone form ( $\mathrm{VK}$ ); and another microsomal enzyme, vitamin $K$ reductase. regenerates the biologically active $V K\left[\mathrm{H}_{2}\right]$ again from the VK (2). The "vitamin $K$ cycle" is inhibited by the typical anticoagulant Warfarin. which depresses the activity of vitamin $\mathrm{K}$ epoxide reductase in vitro (2). Warfarin has also been shown to accumulate endogenous protein substrates for vitamin Kdependent reactions in the body (including precursors of coagulation factors and others) and to inhibit the microsomal gamma-glutamylcarboxylation (gamma-carboxylation) reaction under some special conditions $(3,4)$. Recently, some beta-lactam antibiotics, having the $\mathrm{N}$-methyltetrazolylthiomethyl group at the 3-position of the cephalosporin nucleus, were found to cause hypoprothrombinemia (5-8). Later, Lipsky reported the in vitro inhibition of the liver microsomal gamma-carboxylation reaction by $\mathrm{N}$-methyltetrazolethial (1-methyl-1H-tetrazole-5-thiol. NMTT), and he proposed that it causes hypoprothrombinemia in vivo (9). However, other investigators reported slight or no inhibition of the microsomal 


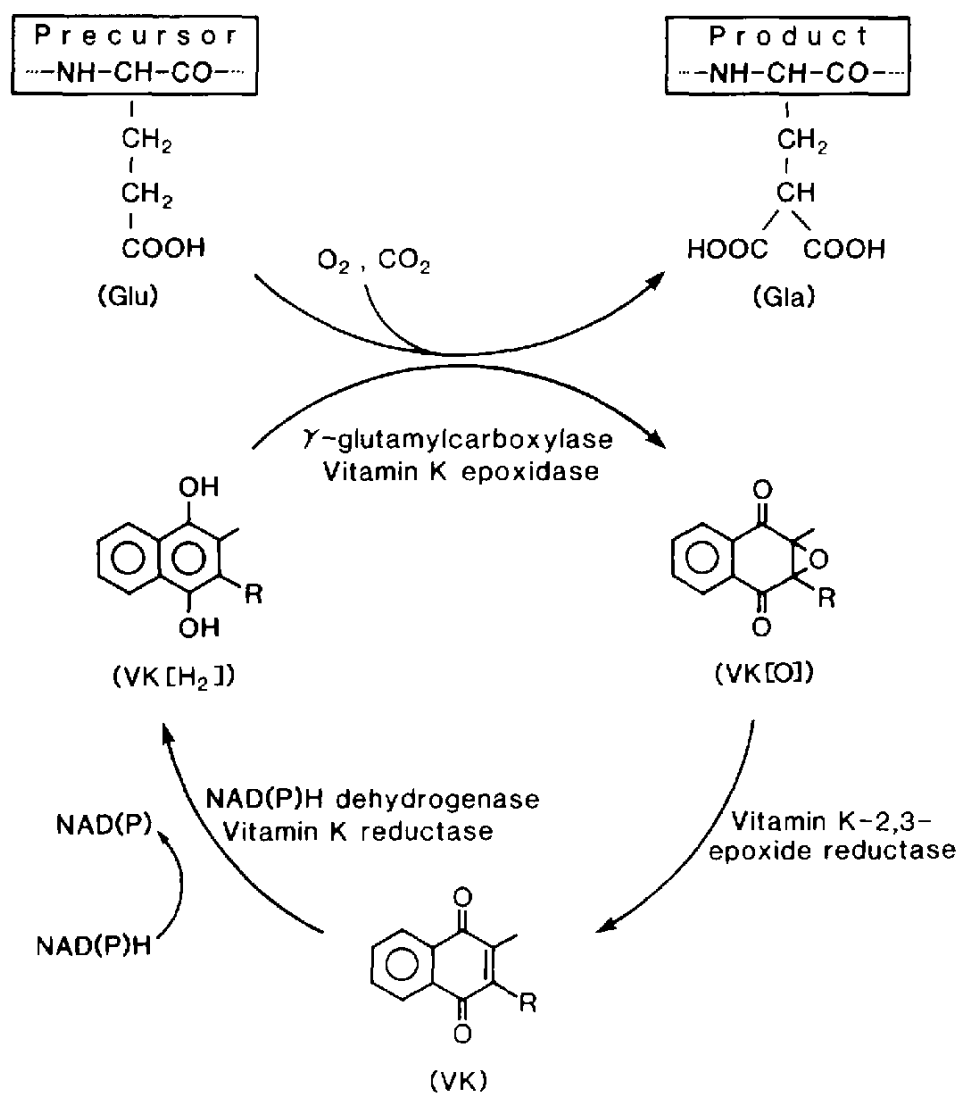

Fig. 1. Vitamin $K$ cycle and gamma-carboxylation.

enzyme activity by NMTT-containing antibiotics and even by NMTT itself (10-12). Since the enzymatic properties of the gammacarboxylation reaction are not fully understood. we checked some of the properties and re-examined the effect of NMTT on the microsomal enzymes to clarify the discrepancies. We describe here the optimum assay conditions for microsomal gammacarboxylation activity, and also offer evidence that NMTT exhibits inhibitory action in vitro on the microsomal enzymes only in some special reaction systems.

\section{Materials and Methods}

Animals: Experiments were carried out using Jcl-Sprague-Dawley male rats (7-9 weeks old) obtained from CLEA Japan. Inc. (Tokyo). The animals were kept in an airconditioned room $\quad\left(24-26^{\circ} \mathrm{C}, \quad 50-60 \%\right.$ relative humidity) lighted 12 hr a day (8.00-
20.00) and fed on a rat diet (Jcl-CA-1) and tap water ad libitum. The animals were housed in suspended wire-bottomed cages to prevent coprophagy.

Chemicals: Phylloquinone $\left(V_{K_{1}}\right)$ was purchased from Nakarai Chemicals, Ltd. (Kyoto), and it was used without further purification. Various forms of vitamin $K$ such as menaquinone-4 (MK-4), VK $K_{1}$ hydroquinone $\left(\mathrm{VK}_{1}\left[\mathrm{H}_{2}\right]\right)$. MK-4 hydroquinone (MK-4[H $\left[\mathrm{H}_{2}\right]$ ), and MK-4 epoxide (MK-4[O]) were synthesized in our laboratories. Pentapeptide substrate, Phe-Leu-Glu-Glu-Leu (13), and the sodium salt of NMTT were also synthesized in our laboratories. Radioactive sodium bicarbonate $\left(\mathrm{NaH}^{14} \mathrm{CO}_{3}, 57.8 \mathrm{mCi} /\right.$ $\mathrm{mmol}$ ) and the tissue solubilizer (NCS) were obtained from Amersham Japan Co., Ltd. (Tokyo), and Scintisol EX-H was from Wako Pure Chemical Industries, Ltd. (Osaka). Other chemicals of the purest grade available 
were obtained commercially and used without further purification.

Preparation of microsomes and solubilization of enzymes: Liver microsomes were prepared from one-day-fasted rats essentially as described by Esmon et al. (14), and the microsomal pellets thus obtained could be stored at $-20^{\circ} \mathrm{C}$ under a nitrogen atmosphere for two weeks without any loss of enzyme activity. When these microsomes were used for experiments, they were suspended in SIK buffer $50 \mathrm{mM}$ imidazole buffer, $\mathrm{pH} 7.2$. including $0.25 \mathrm{M}$ sucrose and $0.5 \mathrm{M} \mathrm{KCl}$ ) containing $0.6 \%(\mathrm{v} / \mathrm{v})$ Triton $X$ 100 to a $30 \%(\mathrm{w} / \mathrm{v})$ solution as calculated from the original liver weight. The resulting suspension (Ms-suspension) was centrifuged at $105.000 \times \mathrm{g}$ for $60 \mathrm{~min}$, and the supernatant fractions obtained (Ms-supernatant) was used as those of solubilized enzymes. In some experiments, the Ms-suspension was used without centrifugation.

Determination of enzyme activity: Unless otherwise specified. microsomal gammacarboxylation activity was determined in 0.5 $\mathrm{ml}$ SIK buffer containing $0.24 \%(\mathrm{v} / \mathrm{v})$ Triton $X-100,1 \mathrm{mM}$ pentapeptide substrate, vitamin $K$ and enzymes. Vitamin $K$ was used in the hydroquinone form $(0.2 \mathrm{mM}$, all values show the final concentration) or the combi nation of the quinone form $(0.1 \mathrm{mM})$ plus $\mathrm{NADH}(2 \mathrm{mM})$. The Ms-supernatant sample was mainly used for the enzymes. In some experiments, pyridoxal-5'-phosphate (PAL$P)$ and/or dithiothreitol (DTT) were added to the reaction mixture. which was preincubated for $30 \mathrm{~min}$ at $17^{\circ} \mathrm{C}$ with moderate shaking under a dark condition. The reaction was initiated by adding $10 \mu$ of $\mathrm{NaH}^{14} \mathrm{CO}_{3}$ solution $(10 \mu \mathrm{Ci}, 0.35 \mathrm{mM})$. The reaction was carried out at $17^{\circ} \mathrm{C}$ for $60 \mathrm{~min}$ and stopped by adding $2 \mathrm{ml} \mathrm{10 \%} \mathrm{trichloroacetic}$ acid (TCA). After the mixture had been left at room temperature for $30 \mathrm{~min}$, it was cen trifuged at $2,000 \times \mathrm{g}$ for $10 \mathrm{~min}$, and the resulting supernatant was transferred to another tube (TCA-soluble components). The components were bubbled with $\mathrm{CO}_{2}(1$ liter/min) for $5 \mathrm{~min}$ to remove any ${ }^{14} \mathrm{CO}_{2}$ remaining in the mixture. Next. $0.5 \mathrm{ml}$ of the gassed sample was mixed with $8 \mathrm{ml}$ of Scintisol EX-H, and the radioactivity was measured with a LSC-672 liquid scintillation counter (Aloka Co., Ltd.. Tokyo). The radioactivity thus determined showed ${ }^{14} \mathrm{CO}_{2}$ incorporation into the exogenous pentapeptide substrate. The precipitate of the reaction mixture after TCA treatment was dissolved in $1.5 \mathrm{ml}$ of $0.2 \mathrm{M}$ sodium carbonate, and the resulting solution was treated essentially as described by Uchida et al. (11) with slight modifications. The radioactivity thus measured showed ${ }^{14} \mathrm{CO}_{2}$ incorporation into endogenous substrates in microsomes. Microsomal protein concentration was determined by using Bio-Rad Protein Assay (15) with bovine serum albumin as a standard.

\section{Results}

Effects of Triton X-100: Various assay methods for microsomal gamma-carboxylation activity have been reported by several investigators $(3,4,13,16-18)$. The assay conditions were compared to estimate the best system. After solubilization of the microsomal enzymes in the presence of $1.5 \%$ Triton X-100, the gamma-carboxylation activity of exogenous peptide substrate was measured in the presence of various concentrations of the detergent. Increasing concentrations of Triton $X-100$ tended to depress the activity (data not shown). After the solubilization of microsomal enzymes in the presence of various concentrations of Triton $X-100$, Ms-supernatant samples were diluted to the required detergent concentrations to determine the enzyme activity. As shown in Fig. 2, the maximum activity was observed in the reaction mixture containing $0.24 \%$ detergent and the activity decreased gradually with increasing concentrations of the detergent. When Ms-supernatant was prepared in the presence of $0.4 \%$ or less of Triton X-100 and the reaction was carried out in the presence of less than $0.24 \%$ detergent, the activity detected was very low probably due to insufficient solubilization of the enzymes (Fig. 2). A similar pattern was obtained for the detergent effect regardless of the form of vitamin $K$ used, although different activity was detected depending on the form of vitamin $\mathrm{K}$ employed. We decided from these results that the Triton $X-100$ concentrations for the solubilization of 
enzymes and the activity determination should be $0.6 \%$ and $0.24 \%$, respectively. Microsomal gamma-carboxylation activity in endogenous protein substrates was not affected markedly by changing the Triton $X$ -

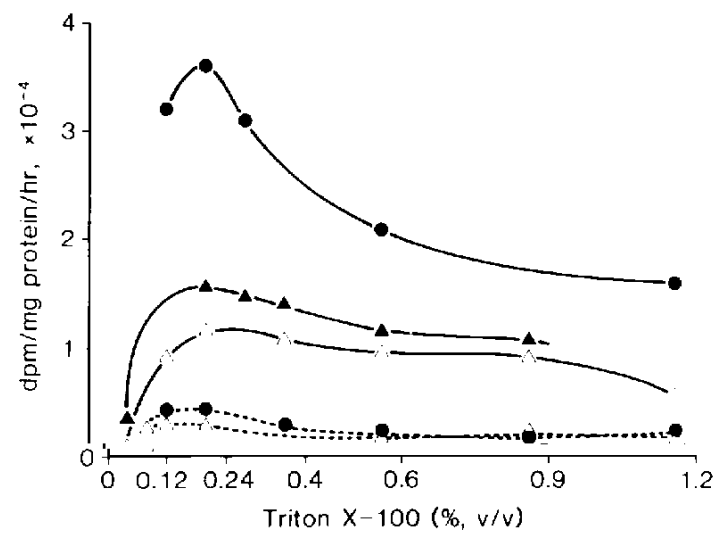

Fig. 2. Effects of various concentrations of Triton $X-100$ on microsomal gamma-carboxylation activity. Enzyme activity was determined using the reaction mixture described in Methods, except that the mixture contained various concentrations of Triton $X-100$. In addition, DTT (1 $\mathrm{mM})$ and PAL-P $(0.8 \mathrm{mM})$ were added to the mixture. Microsomal enzymes were solubilized by adding $0.2-1.5 \%$ Triton $X-100$. and the Ms-supernatant $(0.2 \mathrm{ml})$ thus obtained was used for the assay, except for the reaction mixture containing $1.2 \%$ detergent, in which $0.4 \mathrm{ml} \mathrm{Ms-super-}$ natant was used. The reaction was carried out without preincubation, and the activity detected was plotted as a function of detergent concentration in the reaction mixture. Vitamin $\mathrm{K}$ employed was 0.2 $\mathrm{mM} \mathrm{MK}-4\left[\mathrm{H}_{2}\right]$ (O). $0.2 \mathrm{mMVK}_{1}\left[\mathrm{H}_{2}\right]$ (⿻) or 0.1 $\mathrm{mMVK}$, plus $2 \mathrm{mM}$ NADH ( $\triangle$ ). Solid and dotted lines in the figure represent the gamma-carboxylation activities of exogenous pentapeptide- and endogenous protein substrates, respectively.
100 concentration (Fig. 2). This probably meant that the effect of Triton $X-100$ was specific to the carboxylation reaction for exogenous peptide substrate.

Activation of gamma-carboxylation: Microsomal gamma-carboxylation activity is known to be activated or stimulated by adding DTT or PAL-P $(19,20)$. In the assay system employed, as the concentrations of DTT and PAL-P added to the reaction mixture rose. the enzyme activity increased; $50 \%$ and $260 \%$ increases were observed with $1 \mathrm{mM}$ DTT and $0.8 \mathrm{mM}$ PAL-P, respectively. These reagents were added to the reaction mixture when higher activities were required. Glutathione or cysteine led to slight or no activation of microsomal enzyme activity,

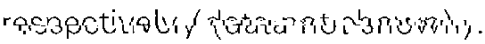

Comparison of various forms of vitamin $\mathrm{K}$ : Vitamin $K$ is an essential cofactor or cosubstrate for gamma-carboxylation (1). Therefore, microsomal enzyme activity was detected by employing various forms of MK-4. The highest activity was observed in the reaction system containing $M K-4\left[\mathrm{H}_{2}\right]$, and the activity was stimulated by the addition of DTT and/or NADH (Table 1). When MK-4 was employed, the carboxylation activity was detected in the presence of MK-4 plus NADH, and further addition of DTT stimulated the activity. On the other hand, only slight activity was detected in the presence of DTT and NADH when MK-4[O] was employed (Table 1). MK-4[H $\left[\mathrm{H}_{2}\right]$ or MK-4 plus NADH was thus used for the assay. When both quinone and hydroquinone forms of $V K_{1}$ were used instead of MK-4 derivatives, similar results were obtained, although the activities differed markedly (data not shown).

Table 1. Liver microsomal gamma-glutamylcarboxylation activity

\begin{tabular}{lrcr}
\hline $\begin{array}{l}\text { Reaction } \\
\text { system }\end{array}$ & MK-4 & Activity (dpm/mg protein/hr) & MK-4[O] \\
\hline Control & $5 \pm 1$ & MK-4[H $\left.\mathrm{H}_{2}\right]$ & $4 \pm 1$ \\
+2 mM DTT & $43 \pm 7$ & $5632 \pm 140$ & $3 \pm 3$ \\
+ $\mathrm{mM} \mathrm{NADH}$ & $3345 \pm 69$ & $7407 \pm 37$ & $10 \pm 3$ \\
+DTT, NADH & $5475 \pm 179$ & $7902 \pm 58$ & $149 \pm 25$ \\
\hline
\end{tabular}

Solubilized microsomal supernatant $(1.02 \mathrm{mg}$ protein) was added to the reaction mixture. For the control, the reaction mixture contained microsomal supernatant, pentapeptide substrate, and $0.24 \%$ Triton $X-100$ in SIK buffer, $\mathrm{pH} 7.2$. Values in the Table represent the mean \pm S.E. of three different determinations. 
Time course of gamma-carboxylation: A typical time course of microsomal gammacarboxylation is shown in Fig. 3, where the $V K_{1}$ plus $\mathrm{NADH}$ system was employed. Incorporation of ${ }^{14} \mathrm{CO}_{2}$ into exogenous pentapeptide substrate increased linearly with time when the mixture was preincubated for 15 or $30 \mathrm{~min}$. On the other hand, the reaction proceeded linearly after several minutes of a lag phase when the preincubation time was 2 min (Fig. 3, solid line). Addition of PAL-P stimulated the reaction, but a similar pattern of time course was obtained (data not shown). ${ }^{14} \mathrm{CO}_{2}$ incorporation into endogenous protein substrates was very rapid and showed almost the same pattern for all preincubation times. Interestingly, the amount of ${ }^{14} \mathrm{CO}_{2}$ incorporated into the endogenous substrates decreased gradually with increasing preincubation time, probably due to the incorporation of $\mathrm{CO}_{2}$ from air which had become dissolved in the reaction mixture, in the presence of $V K_{1}\left[H_{2}\right]$ (Fig. 3 , dotted line). The $\mathrm{pH}$-activity curve showed its optimum between $\mathrm{pH} 7-7.5$ (data not shown), and we decided to use $\mathrm{pH} 7.2$. The assay method finally established from these

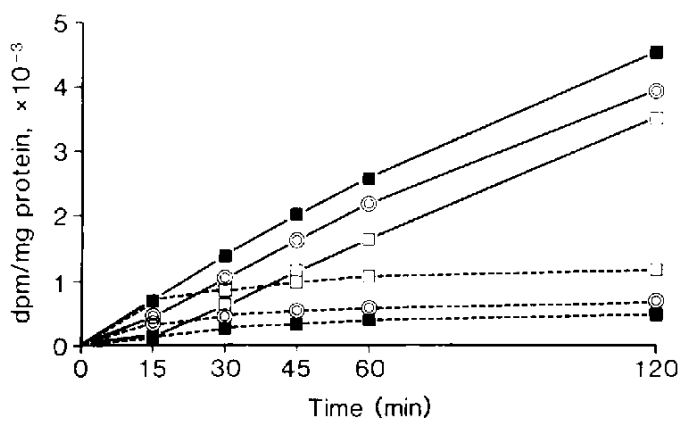

Fig. 3. Time course of microsomal gammacarboxylation reaction. The reaction mixture contained Ms-supernatant, pentapeptide, NADH. VK, and $0.24 \%$ Triton $X-100$ in SIK buffer, $p H$ 7.2. as described in the Methods. After preincubation of the mixture at $17^{\circ} \mathrm{C}$ for $2 \mathrm{~min}(\square) .15 \mathrm{~min}(\circlearrowleft)$, or $30 \mathrm{~min}$ (a) with gentle shaking, the reaction was initiated by the addition of $\mathrm{NaH}^{14} \mathrm{CO}_{3}$ solution. Solid and dotted lines in the figure represent the amount of ${ }^{14} \mathrm{CO}_{2}$ incorporated into the pentapeptide- and endogenous substrates, respectively. Each tube contained $1.13 \mathrm{mg}$ microsomal total protein (Mssupernatant). results (Figs. 2 and 3 , Table 1 ) is described in the Methods.

Comparison of enzyme sample: For the determination of microsomal gammacarboxylation activity, the supernatant fraction of detergent-solubilized microsomes has been used mostly as the enzyme source $\{3,4,13,14,16-20)$. When a detergentsolubilized microsomal suspension was employed for the activity determination without centrifugation, ${ }^{14} \mathrm{CO}_{2}$ incorporation into the exogenous pentapeptide and endogenous protein substrates were observed, although the specific activity thus detected was slightly lower compared with that obtained in the reaction system employing the Mssupernatant (data not shown). Addition of PAL-P or DTT also caused an increase in the enzyme activity even in the reaction system using the Ms-suspension (data not shown). These results indicate that the reaction system employing the Mssuspension can also be used for the assay of microsomal enzyme activity. When rat liver microsomes were used for the activity determination without detergent treatment, the incorporation of ${ }^{14} \mathrm{CO}_{2}$ into substrates was observed only in the reaction system containing NK-4[ $\left.\mathrm{H}_{2}\right]$. On the other hand, the incorporation was detected in both systems, MK-4 $\left[\mathrm{H}_{2}\right]$ and of $V K_{1}$ plus NADH. when the detergent-treated Ms-suspension was employed (Fig. 4). Interestingly, ${ }^{14} \mathrm{CO}_{2}$ incorporation into the pentapeptide substrate increased markedly in the detergentsolubilized Ms-suspension system. The results indicate that detergent-treatment is essential for the determination of microsomal gamma-carboxylation activity.

In vitro effect of NMTT on liver microsomal gamma-carboxylation: As controversial results have been reported on the in vitro action of NMTT on the microsomal gamma-carboxylation reaction $(9,11)$, we re-examined the in vitro effect of NMTT on microsomal enzyme activity using the assay system estimated here. When $V K\left[\mathrm{H}_{2}\right]$ was employed, slight or no inhibitory effect of NMTT was observed. On the other hand. microsomal enzyme activity was inhibited markedly by NMTT in the reaction system containing vitamin $\mathrm{K}$ p/us $\mathrm{NADH}$ (Fig. 5). By adding NMTT, incor- 
(A) Triton $x-100$ free

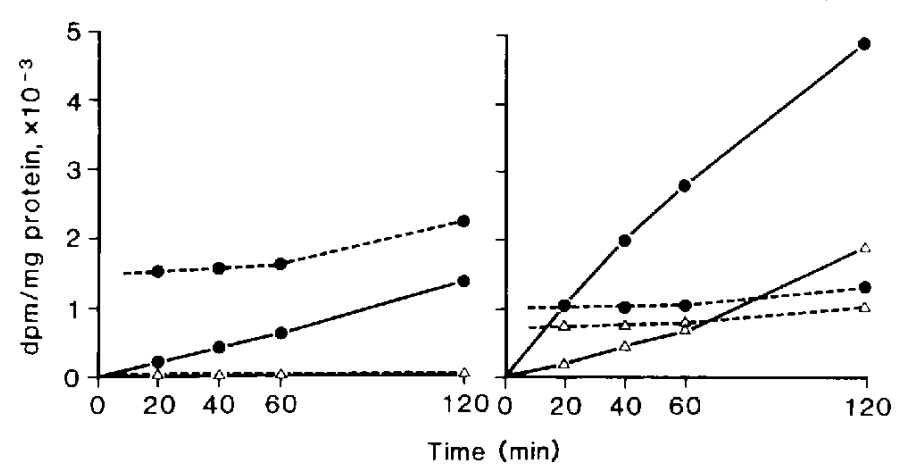

Fig. 4. Comparison of gamma-carboxylation activity between intact and detergent-solubilized microsomes. (A) The enzyme activity was determined using intact liver microsomes in the detergent-free reaction system. (B) Liver microsomes (Ms-suspension) were treated with $1.5 \%$ Triton $X-100$ and the resulting sample $(0.2 \mathrm{ml})$ was added to the reaction mixture (total volume $0.5 \mathrm{ml}$ ). Vitamin $\mathrm{K}$ was added as $\mathrm{MK}-4\left[\mathrm{H}_{2}\right]$ (O) or $V K_{1}$ plus NADH $(\triangle)$. Each tube contained $1.09 \mathrm{mg}$ microsomal total protein. Solid and dotted lines represent the ${ }^{14} \mathrm{CO}_{2}$ incorporation into exogenous pentapeptide and endogenous protein substrates, respectively. Each symbol represents the mean value of three different determinations.

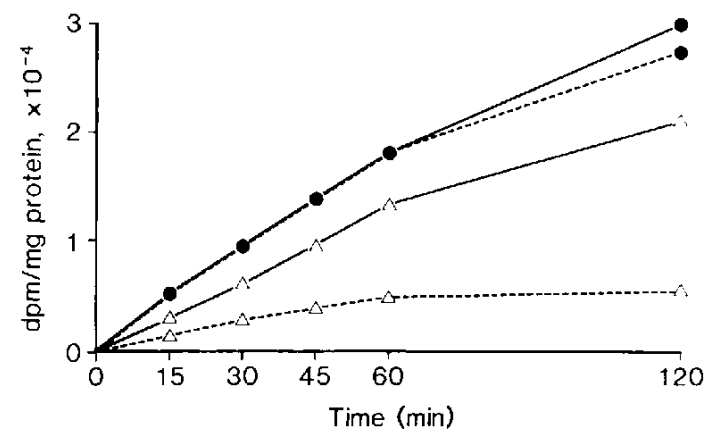

Fig. 5. Effect of NMTT on microsomal gammacarboxylation. The reaction mixture contained 0.8 MM PAL-P, and the vitamin $K$ cofactor employed was MK-4[H $\left.\mathrm{H}_{2}\right]$ (O) or VK, p/us $\mathrm{NADH}(\triangle)$. The reaction was carried out without (solid line) or with (dotted line) $1 \mathrm{mM}$ NMTT. After $30 \mathrm{~min}$ preincubation, the reaction was initiated by adding $\mathrm{NaH}^{14} \mathrm{CO}_{3}$ solution and NMTT when needed. Each tube contained $1.15 \mathrm{mg}$ of microsomal protein (Mssupernatant).

poration of ${ }^{14} \mathrm{CO}_{2}$ into the pentapeptide substrate was suppressed gradually during 60-min incubation, and further incubation did not increase the incorporation of ${ }^{14} \mathrm{CO}_{2}$ into the substrate. The results shown in Fig. 5 indicated that the inhibitory effect of NMTT appeared only under limited reaction conditions.
Effect of NADH on the development of in vitro inhibitory action of NMTT: Suttie et al. (21) and Uchida et al. (K. Uchida, H. Takase and $Y$. Nomura, personal communication) found that NADH was essential to the inhibitory action of NMTT. Table 2 shows the effect of $\mathrm{NADH}$ on the inhibitory action of NMTT to the gamma-carboxylation reaction in vitro. NMTT inhibits the reaction only when the mixture contains NADH in both systems that use the quinone- and hydroquinone form of vitamin $K$. This result supports the previous finding (21). In vitro inhibition of the microsomal gamma-carboxylation enzyme system by NMTT was concentrationdependent (data not shown), and preincubation of the microsomal enzymes together with NMTT and NADH enhanced the inhibitory action of NMTT (Fig. 6).

Modification of the inhibitory action of NMTT: Since the gamma-carboxylation activity was stimulated or suppressed markedly by PAL-P, DTT and Triton X-100, the effects of these components on the in vitro action of NMTT were further examined. Liver microsomes were mixed with the detergent with or without NMTT, and the enzyme activity was determined after preincubation. The activity increased with 15 or 30 min-preincubation, but gradually de- 
Table 2. Effect of NADH to the inhibitory action of NMTT on gamma-glutamylcarboxylation in vitro

Conditions

$+V K+\mathrm{NADH}$
$+V K\left[\mathrm{H}_{2}\right]$
$+V K\left[\mathrm{H}_{2}\right]+\mathrm{NADH}$
Activity (dpm/mg protein/hr)

Control
$2619 \pm 187$
$4670 \pm 124$
$5759 \pm 11$

+ NMTT $(1 \mathrm{mM})$
$1810 \pm 204^{*}$
$4871 \pm 190$
$3578 \pm 50^{* *}$

Inhibition
$-7 \%$
$31 \%$
$0 \%$
$38 \%$

Gamma-carboxylation activity was determined using a microsomal suspension. The reaction system is as described in the Methods, except for the various forms of vitamin $\mathrm{K}$ and NADH which were added as shown in the table. Values in the Table represent the mean \pm S.E. of three different determinations. * **: statistically significant against the control $(P<0.05$ and $P<0.01$, respectively).

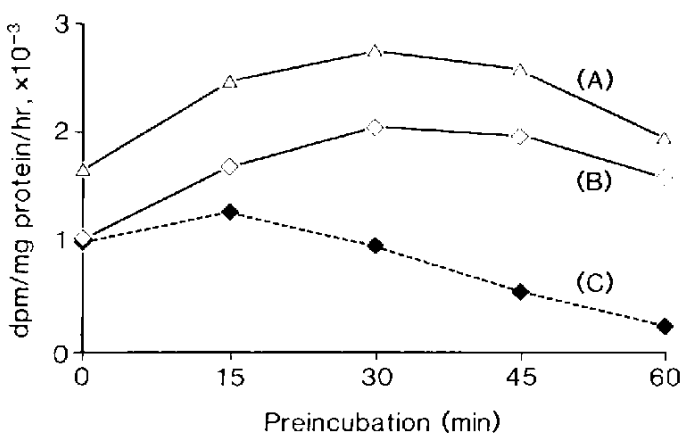

Fig. 6. Effect of preincubation on the inhibitory action of NMTT. Ms-suspension in detergent-free SIK buffer was mixed with the detergent and $V K_{1}$ plus NADH with $(\mathrm{C} ; \cdots \rightarrow \cdots)$ or without $(\mathrm{A} ;-\triangle-)$ $1 \mathrm{mMNMTT}$. The resulting mixture was preincubated at $17^{\circ} \mathrm{C}$ for $15-60$ min with gentle shaking. The reaction was initiated by adding $\mathrm{NaH}^{14} \mathrm{CO}_{3}$ and NMTT when needed $(B ;-O-)$. (A) corresponds to the NMTT-free control and (B) exhibits the effect of NMTT after the reaction started. (C) suggests the additional effect gained during the preincubation with NMTT. Each tube contained $1.24 \mathrm{mg}$ of microsomal total protein (Ms-suspension) and $0.24 \%$ Triton $X-100$. Each point represents the mean value of four different determinations.

creased with further incubation. Although the activity was lower, a similar pattern was obtained when NMTT was added during the reaction period. On the other hand, the activity decreased markedly depending on how long the enzyme samples were preincubated with NMTT plus NADH (Fig. 6). These results indicate that the in vitro action of NMTT was not affected by Triton X-100 under the experimental conditions employed. but the longer preincubation of enzymes with NMTT plus NADH caused more suppression of the activity. A similar inhibitory effect of NMTT was obtained in the reaction system containing PAL-P, although the microsomal enzyme activity was elevated markedly by adding the vitamin (Fig. 7). These results were obtained in both reaction systems using Ms-supernatant and Ms-suspension. These findings indicate that PAL-P does not modify the NMTT action. When the reaction mixture containing various concentrations of DTT was employed, the in vitro action of NMTT disappeared depending on the DTT concentration (data not shown). suggesting that DTT suppresses the action of NMTT.

\section{Discussion}

The enzymes participating in vitamin Kdependent gamma-carboxylation reactions are originally located in the microsomal membranous fraction, and thus detergentsolubilized enzyme samples are generally used for the activity determination $(1,22)$. As described in this paper, the carboxylation activity was hard to detect in the detergentfree reaction system when intact microsomes were used as the enzyme source (Fig. 4). Interestingly, ${ }^{14} \mathrm{CO}_{2}$ incorporation into the endogenous protein substrates was detected in both detergent-free and detergent-containing reaction systems, although the activity was not detected in the detergentfree system when the combination of vitamin $K$ plus NADH was employed (Fig. 4). The results suggest that the detergent increased the solubility of vitamin $\mathrm{K}$ and the interaction between gamma-carboxylase and exogenous pentapeptide substrate. Although the important role of the detergent is clearly to detect the microsomal enzyme activity in 


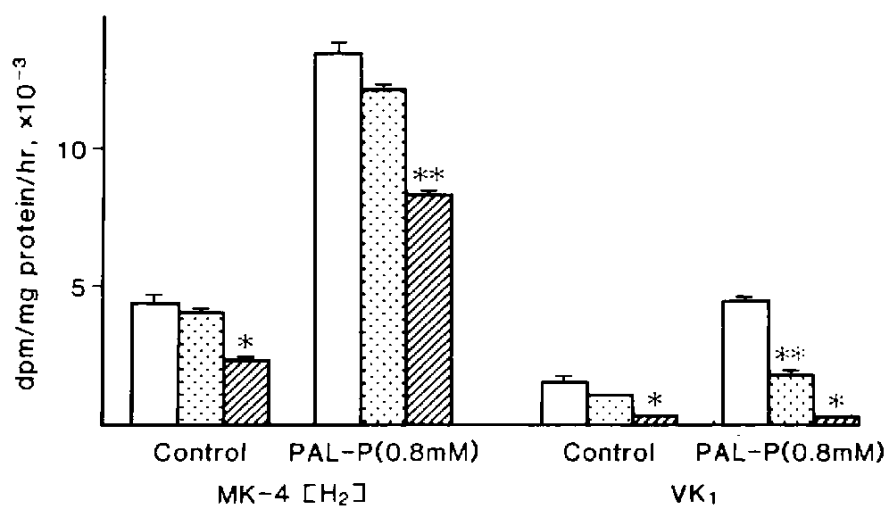

Fig. 7. Effect of PAL-P on the inhibitory action of NMTT. A reaction mixture containing Ms-supernatant (1.9 mg protein). PAL-P. NADH, and $M K-4\left[\mathrm{H}_{2}\right]$ or $V K_{1}$ was used for the experiments. Final cencentrations of PAL-P and NADH were $0.8 \mathrm{mM}$ and $2 \mathrm{mM}$, respectively. NMTT (1 $\mathrm{mM}$ at final concentration) was added before (hatched columns) or after (dotted columns) the preincubation. Other conditions were as given in Methods. Each value represents the mean \pm S.E. of three different determinations. * and **: statistically significant $(P<0.05$ and $P<0.01$, respectively) against the NMTT-free control (open columns).

vitro, higher concentrations do inhibit the enzyme reaction (Fig. 2). This agrees with the report of de Boer-van den Berg et al. in which the inhibitory action of detergent was demonstrated using the solid-phase carboxylase system (18). Thus, the Triton $X-100$ concentration employed for this study is suitable for the solubilization of microsomal enzymes and for the in vitro carboxylation assay. As described previously (21), microsomal gamma-carboxylation activity was detectable using either Ms-supernatant or Ms-suspension as the enzyme source (Figs. 3 and 4 ), and the assay procedure was thus simplified by using either sample. Enhancement of enzyme activity by DTT and PAL-P was observed as reported previously (19, 20), and a similar stimulatory effect of these compounds was observed even in the reaction system using Ms-suspension (data not shown).

The in vitro effect of NMTT on microsomal gamma-carboxylation appeared to depend on the reaction system employed (Fig. 5): the inhibitory effect of NMTT was observed in the reaction mixture containing vitamin $K$ quinone plus $\mathrm{NADH}$, as pointed out by Lipsky $(9,23)$, while the enzyme activity was not affected. as described by Uchida et al. (11), when only the vitamin $\mathrm{K}$ hydroquinone was added to the reaction mixture without
$\mathrm{NADH}$. The results appeared to suggest that vitamin $K$ reductase was inhibited by NMTT followed by a decrease in the gammacarboxylation reaction due to the decreased supply of the vitamin $K$ hydroquinone. However, this was not the case, because the enzyme activity was depressed even in the VK $\left[\mathrm{H}_{2}\right]$-containing reaction system when $\mathrm{NADH}$ was present (Table 2). In a vitamin $\mathrm{K}$ hydroquinone system, the gamma-carboxylation reaction can proceed without any reductant such as $\mathrm{NADH}$. When $\mathrm{NADH}$ is added to such a reaction system it somewhat enhances the enzymic activity in the control experiments: However, microsomal gammacarboxylation activity is inhibited by the coexistence of both NADH and NMTT. Suttie et al. (21) also demonstrated the in vitro inhibitory effect of NMTT on the gamma-carboxylase system in the presence of $\mathrm{NADH}$, and they thought that the primary inhibitory site for NMTT is probably not the vitamin $K$ reductase. As a matter of fact, NMTT can inhibit gamma-carboxylase in the presence of $\mathrm{NADH}$, and can at least do so in an in vitro system. However, the mechanism of this inhibitory reaction remains to be soived.

PAL-P, one of the activators of gammacarboxylase, did not modify the in vitro inhibitory action of NMTT (Fig. 7), while 
DTT diminished it depending on the concentration (data not shown). Lipsky reported that the ability of NMTT to inhibit the gammacarboxylase activity diminished considerably in the presence of glutathione (23). These results indicate that a sulfhydryl group of NMTT, together with NADH, participates in the mechanism of inhibition, but this also needs to be studied further.

NMTT inhibited microsomal gammacarboxylation activity under some restricted assay conditions as mentioned above. It is thus interesting to discuss the correlation between the in vitro inhibitory action of NMTT and the development of hypoprothrombinemia due to NMTT-containing antibiotics. Uchida et al. (11) did not detect any decreased carboxylase activity in liver microsomes prepared from latamoxef- or NMTTtreated rats. We also found no depression of the hepatic gamma-carboxylase activity in rats that were treated with various NMTTcontaining antibiotics, even using Lipsky's assay procedure (T. Oka, A. Touchi and T. Matsubara, unpublished results). On the other hand, hepatic vitamin K-epoxide reductase activity was found to be lower in the antibiotic-treated rats, and NMTT or NMTT-containing antibiotics inhibited also the vitamin $K$ epoxide reductase activity in vitro (K. Kawamoto, K., Sugeno, A. Touchi and T. Matsubara, unpublished results). These results suggest that NMTT affects vitamin $\mathrm{K}$-epoxide reductase in vivo, but not gamma-carboxylase directly. Thus, we concluded that vitamin $\mathrm{K}$-dependent gammacarboxylase is inhibited in vitro by NMTT only in the presence of NADH, with the mechanism not being responsible for hypoprothrombinemia associated with antibiotic therapy.

Acknowledgments: We sincerely thank Drs. $M$. Narisada and $M$. Ohtani for their preparation of the various forms of vitamın $K$, and we also thank $D r$. $K$. Inouye for synthesizing the pentapeptide substrate.

\section{References}

1 Suttie, J.W.: Mechanism of action of vitamin K: synthesis of gamma-carboxyglutamic acid. CRC Crit. Rev. Biochem. 8, 191-223 (1980)

2 Whitlon, D.S., Sadowski, J.A. and Suttie, J.W.:
Mechanism of coumarin action: Significance of vitamin $K$ epoxide reductase inhibition. Biochemistry 17, 1371-1377 (1978)

3 Roncaglion, M.C., Soute, B.A.M., de Boer-van den Berg, A.G. and Vermeer, C.: Warfarininduced accumulation of vitamin $\mathrm{K}$-dependent proteins. Comparison between hepatic and nonhepatic tissues. Biochem. Biophys. Res. Commun. 114, 991-997 (1983)

4 Wallin, R. and Martin, L.F.: Vitamin K-dependent carboxylation and vitamin $\mathrm{K}$ metabolism in liver. Effect of warfarin. J. Clin. Invest. 76, 18791884 (1985)

5 Hooper, C.A., Haney, B.B. and Stone, H.H.: Gastrointestinal bleeding due to vitamin $K$ deficiency in patients on parenteral cefamandole. Lancet i, 39-40 (1980)

6 Reddy, J. and Bailey, R.R.: Vitamin K deficiency developing in patients with renal failure treated with cephalosporin antibiotics. N.Z. Med. J. 92, 378-380 (1980)

7 Weitekamp, R.M. and Aber, R.C.: Prolonged bleeding times and bleeding diathesis associated with moxalactam administration. JAMA 249, 69-71 (1983)

8 Haubenstock, A., Schmidt, P., Zazgornik, J., Balcke, P. and Kopsa, H.: Hypoprothrombinemic bleeding associated with ceftriaxone. Lancet i, 1215-1216 (1983)

9 Lipsky, J.J.: N-Methyl-thio-tetrazole inhibition of the gamma-carboxylation of glutamic acid: possible mechanism for antibiotics associated hypoprothrombinaemia. Lancet ii, 192-193 (1983)

10 Uotila, L. and Suttie, J.W.: Inhibition of vitamin $\mathrm{K}$-dependent carboxylase in vitro by cefamandole and its structural analogs. J. Infect. Dis. 148, 571-578 (1983)

11 Uchida, K., Ishigami, T. and Komeno, T.: Effects of latamoxef and methyltetrazolethiol on gammaglutamylcarboxylase activity. Japan. J. Pharmacol. 35, 330-333 (1984)

12 Smith, G.F. and Sundboom, J.L.: The effects of 1 -methyl-5-thiotetrazole in a rat liver vitamin $\mathrm{K}$ dependent carboxylase assay. Thromb. Res. 33, 633-644 (1984)

13 Suttie, J.W., Hageman, J.M., Lehrman, S.R. and Rich. D.H.: Vitamin K-dependent carboxylase: development of a peptide substrate. J. Biol. Chem. 251, 5827-5830 (1976)

14 Esmon, C.T., Sadowski, J.A. and Suttie, J.W.: A new carboxylation reaction: the vitamin $K$ dependent incorporation of $\mathrm{H}^{14} \mathrm{CO}_{3}{ }^{-}$into prothrombin. J. Biol. Chem. 250, 4744-4748 (1975)

15 Bradford, M.M.: A rapid and sensitive method 
for the quantitation of microgram quantities of protein utilizing the principle of protein-dye binding. Anal. Biochem. 72, 248-254 (1976)

16 Mack, D.O., Suen, E.T., Girardot, J.M., Miller, J.A., Delaney, R. and Johnson, B.C.: Soluble enzyme system for vitamin K-dependent carboxylation. J. Biol. Chem. 251, 3269-3276 (1976)

17 Houser, R.M., Carey, D.J., Dus, K.M.. Marshall, G.R. and Olson, R.E.: Partial sequence of rat prothrombin and the activity of two related pentapeptides as substrates for the vitamin $\mathrm{K}$ dependent carboxylase system. FEBS Lett. 75, $226-230$ (1977)

18 de Boer-van den Berg, M.A.G., Urlich, M.M.W., Hemker, H.C., Soute, B.A.M. and Vermeer, C.: Vitamin K-dependent carboxylase: the carboxylation of exogenous substrates in different systems. Biochim. Blophys. Acta 831, 94-98 (1985)

19 Suttie, J.W., Lehrman, S.R., Geweke, L.O.,
Hageman, J.M. and Rich, D.H.: Vitamin Kdependent carboxylase: requirement for carboxylation of soluble peptide substrates and substrate specificity. Biochem. Biophys. Res. Commun. 86, 500-507 (1979)

20 Dubin, A., Suen, E.T., Delaney, R., Chiu, A. and Johnson, B.C.: Stimulation of vitamin Kdependent carboxylation by pyridoxal-5'-phosphate. Biochem. Biophys. Res. Commun. 88, 1024-1029 (1979)

21 Suttie, J.W., Engelke, J.A. and McTigue, J: Effect of $\mathrm{N}$-methyl-thiotetrazole on rat liver microsomal vitamin $\mathrm{K}$-dependent carboxylation. Biochem. Pharmacol. 35, 2429-2433 (1986)

22 Johnson, B.C.: Vitamin K-dependent carboxylase. Methods Enzymol. 67, 165-180 (1980)

23 Lipsky, J.J.: Mechanism of the inhibition of the gamma-carboxylation of glutamic acid by $\mathrm{N}$ methylthiotetrazole-containing antibiotics. Proc. Natl. Acad. Sci. U.S.A. 81, 2893-2897 (1984) 